\title{
Çok amaçlı eksternal fiksatör
}

\section{Multi-purpose external fixator}

\author{
Mahir Gülşen
}

Ortopedia Hastanesi, Adana

\begin{abstract}
Ortopedi ve travmatolojide, tüm eksternal fiksatör endikasyonlarında kullanılabilecek şekilde tasarlanan Çok Amaçlı Eksternal Fiksatör, ayarlanabilir çivi fiksatörü tipinde olup erişkin ve çocuk tipleri vardır. Fiksatör, oluklu çubuk, kayıcı parça, çivi taşıyıcı ve kompresyon distraksiyon parçasından oluşmaktadır. Fiksatörün universal topuz-yuva tarzı eklem yerleri sayesinde tespitli kemikte her yöne döndürme ve yer değiştirme mümkün olmaktadır. Fiksatör tek veya çok düzlemli, unilateral veya bilateral kullanılabilir.
\end{abstract}

Anahtar sözcülkler: eksternal fiksasyon; çok planlı eksternal fiksatör

\section{T. C. Türk Patent Enstitüsü'ne Faydalı Model Belgesi için Başvuru Bilgileri[ ${ }^{1]}$}

Başvuru bilgileri Tablo 1'de gösterilmiştir. ${ }^{[1]}$

Tablo 1. Başvuru bilgileri ${ }^{[1]}$

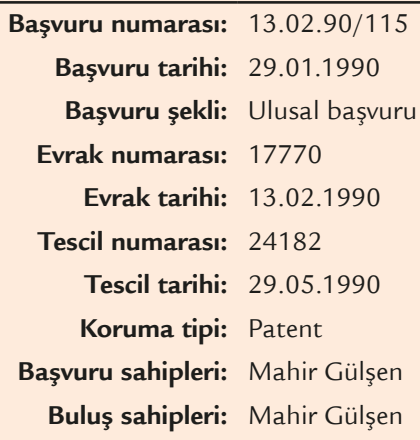

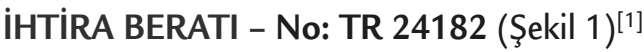

\section{Teknik Alan ${ }^{[1]}$}

“Ortopedi ve Travmatoloji'de, tüm eksternal fiksatör endikasyonlarında kullanılabilecek şekilde tasarlanan Çok Amaçlı Eksternal Fiksatör, ayarlanabilir çivi fiksatörü tipinde olup erişkin ve çocuk tipleri vardır."

\begin{abstract}
A multiplanar and adjustable external fixator which can be used for almost all external fixation indications in both adult and paediatric age groups was developed. Parts of the fixator are hollowed bar, sliding part, pin holder, compression and distraction apparatus. Pin holder has bone and socket articulation that allows multiplanar fixation. The fixator can be used as unilateral or bilateral manner.
\end{abstract}

Key words: external fixation; multiplanar external fixator

- İletişim adresi: Prof. Dr. Mahir Gülşen, Ortopedia Hastanesi, Cumhuriyet Cad. No: 64, Seyhan, Adana Tel: 0532 - 3411975 e-posta: mahirgulsen@gmail.com ORCID iD: 0000-0002-7268-5024

- Geliș tarihi: 9 Kasım 2020 Kabul tarihi: 26 Kasım 2020 


\section{Buluşun Kısa Tarifi ${ }^{[1]}$}

“Ortopedi ve Travmatoloji'de, tüm eksternal fiksatör endikasyonlarında kullanılabilecek şekilde tasarlanan Çok Amaçı I Eksternal Fiksatör, ayarlanabilir çivi fiksatörü tipinde olup erişkin ve çocuk tipleri vardır (Şekil 2). Fiksatör oluklu çubuk, kayıcı parça, çivi taşıyıcı ve kompresyon distraksiyon parçasından oluşmaktadır. Fiksatörün universal topuz-yuva tarzı eklem yerleri sayesinde tespitli kemikte her yöne döndürme ve yer değiştirme mümkün olmaktadır. Fiksatör tek veya çok düzlemli, unilateral veya bilateral kullanılabilir."

\section{Buluşun Detaylı Açıklanması ${ }^{[1]}$}

"Bu fiksatör, ortopedi ve travmatoloji alanında ve hareket sisteminin rekonstrüktif cerrahisinde kullanılmak üzere geliştirilmiştir.

Eksternal fiksatörlerle tedavi, yöntemin kullanışlı ve kolay olması nedeniyle giderek yaygınlaşmaktadır. Bu sahada pek çok eksternal fiksatör geliştirilmiş olup, bunlar basit çivi fiksatörleri, ayarlanabilir çivi fiksatörleri ve halka fiksatörleri olarak üç sınıfa ayrılabilirler.

Bir eksternal fiksatör, fiksatör kemiğe uygulandıktan sonra çivilerin yerleri değiştirilmeden gerekli düzeltmeler yapılabilmesine izin vermelidir. Yani tespitli kemik, her üç düzlem ve eksende yer değişsirip döndürülebilmelidir. Çok Amaçı Eksternal Fiksatör, ayarlanabilir çivi fiksatörü tipinde olduğundan bu özelliklere sahip olup, ayrıca kayıcı parçasının vidası gevşetilerek veya sıkılmak suretiyle dinamik ya da statik olarak kullanılabilmektedir.

Çok amaçlı eksternal fiksatörün parçaları ve şekildeki parça numaraları (Şekil 3):

1. Oluklu çubuk (Şekil 3, 11A ile gösterilen bölüm): Fiksatörün dış destek çubuğu olup standart tipte boydan boya, pelvik tipte her iki uçta olukludur.

2. Kayıcı parça (Şekil 3; 1, 2, 4 ve 5 ile gösterilen bölümler): Oluklu çubuk üzerinde hareket etmekte ve bir vida (Şekil 3, 13 ile gösterilen bölüm) ile çubuğa tespit edilmektedir.

3. Çivi taşıyıcı (Şekil 3; 6, 7 ve 8 ile gösterilen bölümler): Kayıcı parçaya, her yöne dönebilen topuz-yuva tarzı eklemle bağlanmıştır. Taşıııcının platformu (Şekil 3, 7 ile gösterilen bölüm) üniversal eklemle (Şekil 3, 8 ile gösterilen bölüm) açılı olarak birleşmektedir. Bu eğim sayesinde fiksatör pelviste de kullanılabilmektedir. Universal eklem hem somun (Şekil 3, 5 ile gösterilen bölüm) hem vidalarla (Şekil 3, 3 ile gösterilen bölümler) sıkıştırılmakta ve böylece stabil bir bağlantı yeri temin edilmektedir. Çivi taşıyıcıya çeşitli çaplarda (2.5-6 mm) çivi takılabilmektedir. Çiviler takıldıktan sonra taşıyıcının kapăğ vidalarla (Şekil 3, 14 ile gösterilen bölüm) sıkıştırılmaktadır.
4. Kompresyon-distraksiyon parçası (Şekil 3; 9, 10 ve 12 ile gösterilen bölümler): Bu parça, gerektiği durumlarda oluklu çubuğa vida (Şekil 3, 14 ile gösterilen bölüm) ile sıkıştırılarak monte edilmekte ve kompresyon ya da distraksiyon yapılmaktadır. Vidasının (Şekil 3, 10 ile gösterilen bölüm) her bir adımı $1 \mathrm{~mm}$ olup gerektiğinde kemik uzatmalarında da kullanılmaktadır."

\section{Temel Uygulama[1]}

“1. Çivi taşıyıcının üzerindeki oluklar rehber olarak kullanılıp çiviler kemiğe yerleştirilir.

2. Tüm çiviler yerleştirildikten sonra çiviler çivi taşıyıcının oluklarına oturtulur ve taşıyıcının kapağı vidalarla sıkıştırılır.

3. Fiksatör çubuğu, kayıcı parçanın vidasının ucu oluk içerisinde kayabilecek şekilde yerleştirilir. Kemikler ve çiviler uygun pozisyonda tutulurken önce topuz yuva ekleminin somunu, sonra da çivi taşııııının altındaki ve somun kenarındaki vidalar sıkıştırılarak kilitleme yapılır.

4. Kayııı parçanın vidaları sıkıştırılır.

5. Takılıp çıkartılabilen kompresyon-distraksiyon parçası ile gerektiği hallerde kompresyon veya distraksiyon yapılır.”

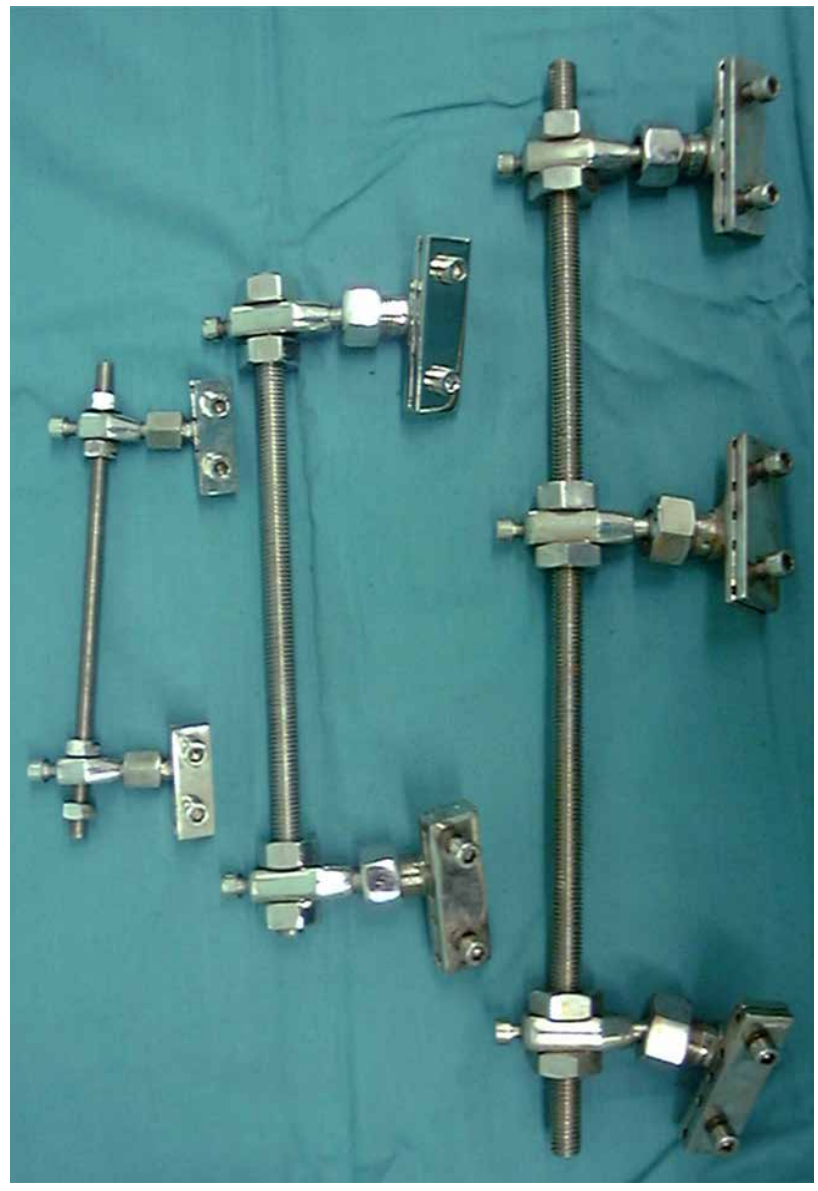

Şekil 2. Çok amaçlı eksternal fiksatör. 


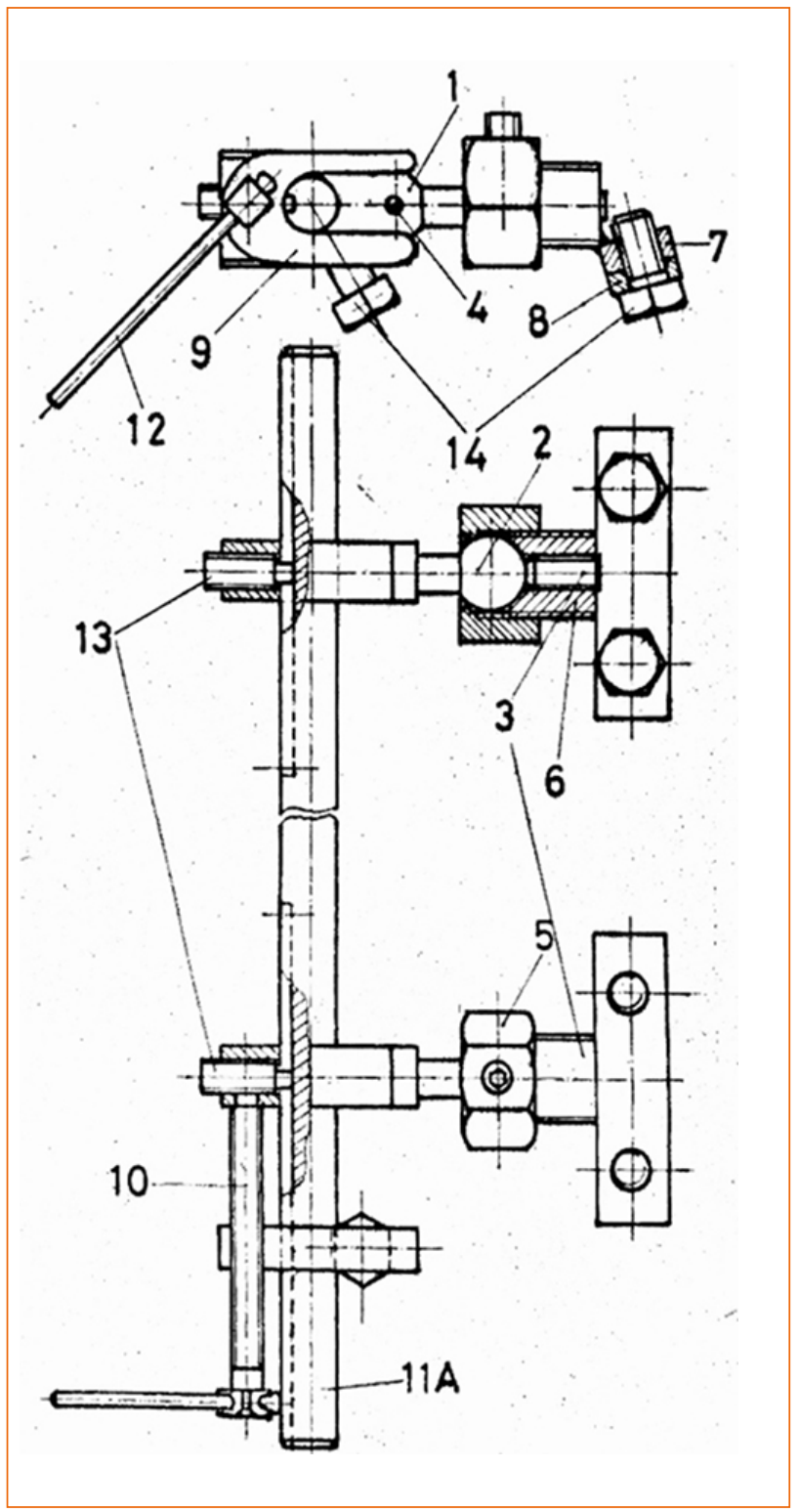

Şekil 3. Çok amaçlı eksternal fiksatör parçaları.

\section{Metalip (İstemler) ${ }^{[1]}$}

"1. Çeşitli klinik durumlar için geliştirilmiş olan "çok amaçı eksternal fiksatör"ün en önemli özellikleri; ayarlanabilir tipte bir fiksatör olması ve fiksatöre tespitli kemiklerin her yöne yer değiştirip dönmesine izin vermesidir. Bu nedenle mevcut parçaları ile eksternal fiksatörlerin tüm endikasyonları için kullanılabilecek durumdadir.

2. Metaliple uygun bir oluklu çubuk (Şekil 3, 11A ile gösterilen bölüm) olup, fiksatör dinamik olarak kullanılırken kayıcı parçanın vidası (Şekil 3, 13 ile gösterilen bölüm) gevşetildiğinde orijinal bir parça olan bu oluklu çubuk sayesinde kemiklerde dönme meydana gelmez, sadece aksiyel istikamette yer değiştirmeler olur.

3. Metaliple uygun kilitli bir topuz-yuva eklemi olup bu eklemin özelliği, kayıcı parçanın topuzu (Şekil 3, 2 ile gösterilen bölüm), çivi taşıyıcıya somun (Şekil 3, 5 ile gösterilen bölüm) ve iki adet vida (Şekil 3, 3 ile gösterilen bölüm) ile sıkıştırıldığında klinik amaca uygun pozisyonda hareketsiz bir eklem sağlamasıdır.

4. Metaliple uygun bir kompresyon-distraksiyon parçası (Şekil 3; 9, 10, 12 ve 14 ile gösterilen bölümler) olup özelliği, oluklu çubuğa takılıp çıkarılabilmesi, her adımı $1 \mathrm{~mm}$ olan vidası (Şekil 3, 10 ile gösterilen bölüm) ile takılma yönüne göre kompresyon veya distraksiyon yapmaya yaramasıdır.”

\section{YAZARIN KONUYLA ILGILI ÇALIŞMALARI}

Çok amaçlı eksternal fiksatör ile ilgili tasarım ve imalat sonrası fiksatörün mekanik verimi hem teorik hem de deneysel olarak incelenmiştir (Şekil 4). ${ }^{[2-6]}$ Daha sonra, elde edilen verilerin ışığı altında klinik uygulamalara geçilmiş (Şekil 5 ve 6 ) ve elde edilen sonuçlar yayımlanmıştır. ${ }^{[7,8]}$

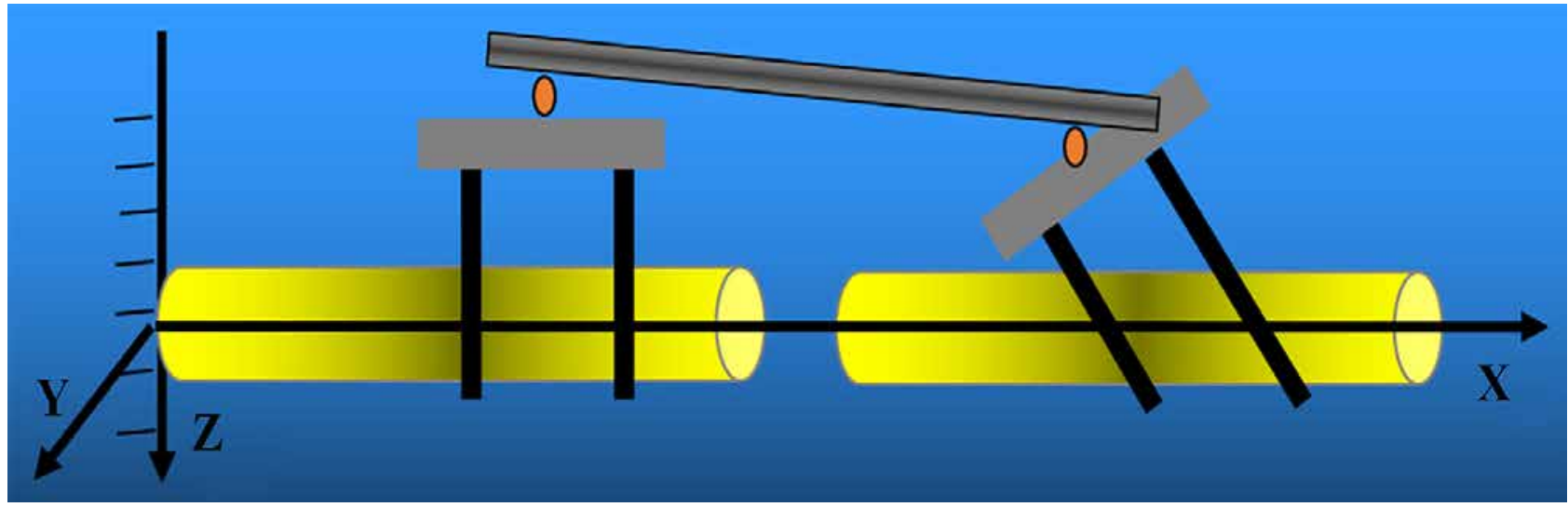

Şekil 4. Uzaysal monolateral fiksatör. 


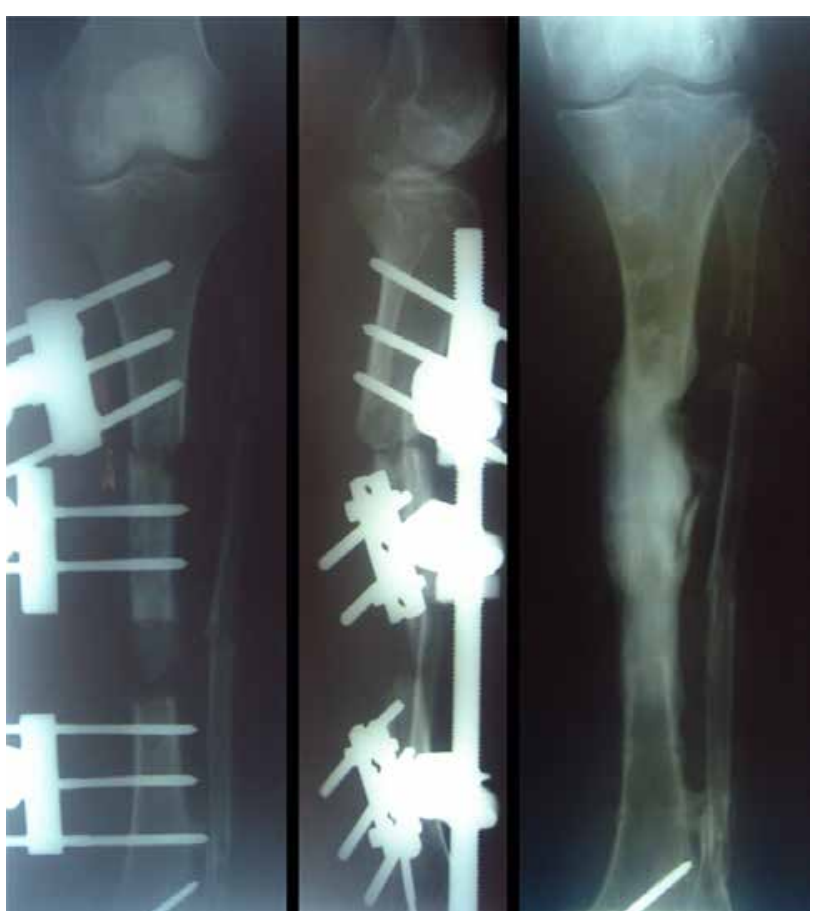

Şekil 5. Kemik kaydırma uygulaması.

\section{KAYNAKLAR}

1. T.C. Sanayi Bakanlığı İhtira Beratı - No: TR 24182, 1990.

2. Gülşen M, Karakaş ES. Çok amaçlı eksternal fiksatör 1: Tanıtım ve uzun kemik kırıklarındaki mekanik verim. Ortopedi Travmatoloji ve Rehabilitasyon Derg 1988;2:8-15.

3. Gülşen M, Karakaş ES, Aycan K. Çok amaçlı eksternal fiksatör 2: Pelvis ve vertebra yaralanmalarındaki mekanik verim. Ortopedi Travmatoloji ve Rehabilitasyon Derg 1988;2:70-4.

4. Tan I, Gülşen M, Bayram H, Baytok G. Çivilerin kırık hattına uzaklığının ve etkin çivi boyunun eksternal fiksatör sıkılığına etkisi. Çukurova Üniversitesi Tıp Fakültesi Derg 1990;15:540-3.

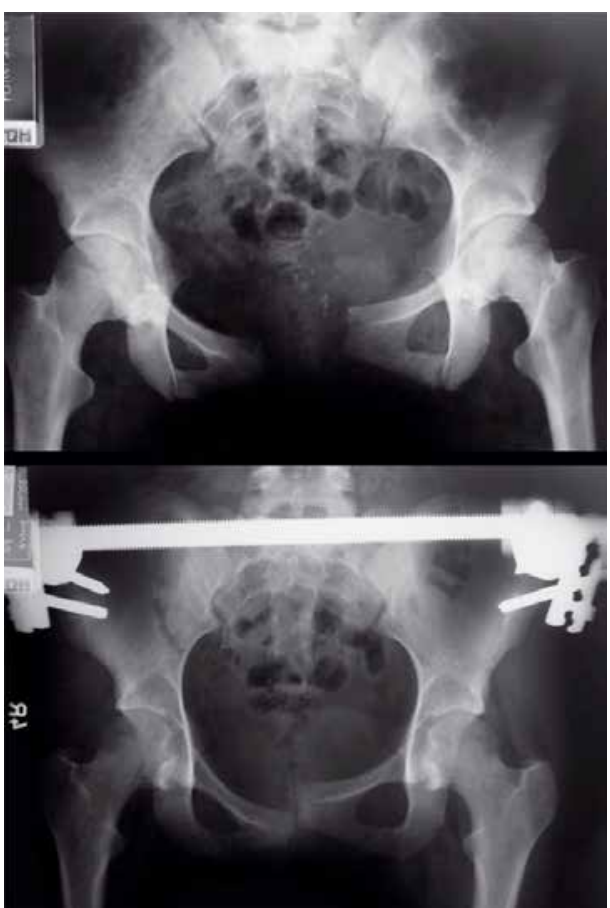

Şekil 6. Pelvis yaralanmasında uygulama.

5. Ün K, Akcalı ID, Gülşen M. A Theroretical and Experimental investigation of Lateral Deformations in a Unilateral External Fixator. J Med Devices 2007;1:165-72. Crossref

6. Akçalı ID, Gülşen M, Ün K. Kas İskelet Sistemi Biyomekaniği. Ankara: Rekmay; 2009.

7. Gülşen M, Baytok G, Herdem M, Sarpel Y. Çok amaçlı eksternal fiksatör: Klinik uygulamalar ve erken sonuçları. XI. Milli Türk Ortopedi ve Travmatoloji Kongresi, 27-30 Eylül 1989, Ankara. XI. Milli Türk Ortopedi ve Travmatoloji Kongre Kitabı. Ankara: Emel Matbaacılık; 1990. p.241-4.

8. Sarpel S, Gülşen M, Toğrul E, Baytok G. Treatment of type III open fractures of the lower and of femur with a modular monolateral external fixator. Hacettepe J Orthop Surg 1996;3:155-8. 